\title{
PATRIMÔNIO IMATERIAL: O TAMBOR DE CRIOULA
}

Maristela ROCHA*

\author{
*Mestre em Comunicação e Cultura pela UFRJ, jornalista, professora universitária. \\ maristelarocha.rocha@gmail.com \\ maristelarocha@yahoo.com
}

\section{Recebido em: 21/04/2014 - Aprovado em: 30/06/2014 - Disponibilizado em: 30/07/2014}

\section{RESUMO:}

Pretendemos investigar o Tambor de Crioula como patrimônio cultural imaterial brasileiro, com ênfase em sua manifestação no Maranhão. Cantos, danças, indumentárias, instrumentos, comidas e bebidas aparecem como peculiaridades. Há o intuito, ainda neste trabalho, de abordar as modificações na contemporaneidade, bem como o trabalho de preservação como patrimônio institucionalizado. Além do aspecto de resistência e religioso, o Tambor de Crioula também é marcado pela potencialidade lúdica. Como diferencial quanto a outras danças de origem afrobrasileira, o Tambor, dança circular sem coreografia rigidamente definida, apresenta a punga: um convite para entrar na roda. Quem está no centro e quer sair, avança em direção a outra companheira, aplicando-lhe a punga (que consiste no toque com a barriga). A mulher que estiver na roda vai para o centro e dá-se a continuidade da brincadeira com as próximas pungadas. Apontaremos, ainda, as instituições pioneiras nas ações de salvaguarda do Tambor de Crioula como patrimônio intangível.

Palavras-chave: Tambor de Crioula. Punga. Maranhão. São Benedito. Patrimônio cultural imaterial.

\section{ABSTRACT:}

We intend to investigate the "Tambor de Crioula" as intangible cultural heritage, emphasizing on its manifestation in Maranhão/Brazil. Songs, dances, costumes, instruments, food and beverages appear as peculiar characteristics. There is the intention to address the changes in contemporary society as well as the work of preservation as institutionalized equity. Besides the religious aspect of resistance, the "Tambor de Crioula" is also marked by playful potential. What about the difference to other dances african-Brazilian the "Tambor de Crioula", circular dance without rigidly defined choreographies, presents the "punga", an invitation to join the circle. Who is in the center and either quit advances toward another companion, applying his "punga" (consisting in touch with the belly). The woman that is in the centre gives the continuity of play on the next "pungadas". Also this article will point out the pioneering institutions in actions for safeguarding intangible heritage as the "Tambor de Crioula".

Keywords: Tambor de Crioula. Punga. Maranhão. St. Benedict. Intangible cultural heritage.

\section{TAMBOR DE CRIOULA, PUNGA, PUNGADA:}

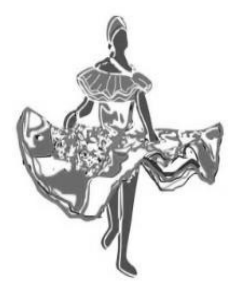

Mexe, remexe, rebola é tambor de crioula A ginga descente envolvente é tambor de crioula

É sensualidade pura, não dá pra segurar

Faz qualquer tristeza se alegrar

(...)

Quero ver ferver, o tambor de crioula

ê ê ê... criooula... criooula... (crioula) criooulaaaaa... criooula *CANTOS DE CONGO
Encontrada, especialmente, no estado do Maranhão, o Tambor de Crioula, Punga ou

Pungada, é uma dança afro-brasileira cuja principal característica coreográfica é a formação de um círculo com solistas dançando e se alternando no centro da roda. Segundo informações da Enciclopédia da Música Brasileira (1998), ao toque do tambor grande, um figurante dá dois passos a frente e uma rodada, encaminhando-se, posteriormente, na direção de quem vai levar 
a punga (o convite para entrar na roda e se dirigir ao centro).

No meio do círculo, os movimentos corporais são mais livres e acentuados, mas sempre acompanham o pulso e o ritmo marcados pelos instrumentistas. A punga ${ }^{\mathrm{i}}$, então, varia de dançante para dançante, sendo caracterizada pelo encontro, uma rápida batida entre as barrigas das mulheres que darão, dessa forma, a pungada, ou seja, a umbigada.

Não há calendário ou locais específicos para a realização do Tambor de Crioula, que é executado, especialmente, em louvor a São Benedito ${ }^{\mathrm{ii}}$ (1524-1589). Acontece, principalmente, nas festas carnavalescas e juninas realizadas no Maranhão, além de encerrar as festas de

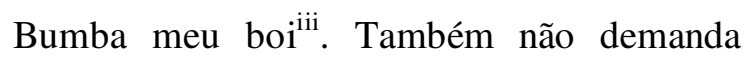
transe ou possessão, como outras manifestações afrodescendentes.

Pode, ainda, ser realizado como forma de pagamento de promessas a outros protetores católicos ou entidades cultuadas nos terreiros. As mulheres, nesse caso, carregam nos braços ou na cabeça a imagem do santo de devoção. Conforme explica o pesquisador Marco Aurélio Haikel:

\footnotetext{
(...) a constatar pelas centenas de grupos de tambor de crioula existentes: "Brincadeira de S. Benedito", "Unidos de S. Benedito", "Filhos de S. Benedito", "Orgulho de S. Benedito", etc., acrescentando-se que ao início de cada "brincada", a primeira salva é dirigida ao Santo, que no culto religioso de influência africana, hegemônico no Maranhão, Mina (com tradição Jeje-Nagô), é
}

relacionado à divindade Vodun, Avêrêkête (HAIKEL, 2005 ${ }^{\text {iv }}$ ).

Provavelmente, o Tambor de Crioula chegou ao Maranhão trazido por escravos de várias regiões da África, como Guiné, Costa da Mina, Congo e Angola. Não é possível, entretanto, definir uma data precisa:

\begin{abstract}
Embora não seja possível apurar com exatidão as origens históricas do tambor de crioula, na memória dos brincantes mais velhos e em fontes históricas, podem se encontrar registradas, desde o século XIX, referências a cultos religiosos concebidos como formas de lazer, devoção e resistência (FIGUEIREDO E OLIVEIRA, 2012 ${ }^{\mathrm{v}}$ ).
\end{abstract}

Muitos eram os folguedos, jogos, bailes, as danças e cantorias de exaltação aos santos preferidos, embora sofressem discriminação por parte da elite dominante. Isso acontecia também com o Tambor de Crioula, por um longo tempo proibido pelas autoridades.

A marginalização social e econômica do afrodescendente era sistematizada através da exclusão do elemento de cor negra pelas instituições. Essa "desqualificação" atingia todas as esferas, inclusive a cultural, como explica o teórico Muniz Sodré:

(...) Os costumes, os modelos de
comportamento, a religião e a própria
cor da pele foram significativos como
handicaps negativos para os negros
pelo processo socializante do capital
industrial (SODRÉ, 1998, p. 14). A tentativa de deslegitimar tais expressões populares resultava em perseguição policial. Parafraseando o teórico Muniz Sodré, a equação racismo = 
colonialismo é perfeita (SODRÉ, 1999). Equação essa presente em toda a história do Brasil.

Eram rígidos também a discriminação e o controle por parte das instituições policiais. Devido ao patrulhamento, devia-se solicitar licença e pagar tributos para a realização dos festejos populares:

$\mathrm{Na}$ sociedade maranhense, prevalecia o preconceito. Jornais locais registravam inúmeras reclamações contra os divertimentos de negros. Só em 1938 é que Mário de Andrade faz a primeira documentação sobre a dança, em sua Missão de Pesquisas Folclóricas, registrando manifestações populares do Norte e do Nordeste do Brasil (FERRETTI, $2012^{\mathrm{vi}}$ ).

Estabelecia-se, dessa forma, uma dualidade cultural relativa às relações de dominação social: os saraus nos salões e nas residências; os sambas, lundus e batuques nos terreiros. Quanto ao intercâmbio e articulações dos gêneros culturais, cabe-nos ressaltar que “a palavra 'sincretismo' serve em geral como um biombo 'harmônicopluralista' para esconder a realidade da discriminação" (SODRÉ, 1999, p. 127).

O mesmo ocorria no cenário urbano, em locais que as irmandades de homens afrodescendentes acolhiam os escravos e forros através de cultos religiosos e de associações, propiciando o desenvolvimento de "seus autos singulares, tais como os moçambiques, os congos, os maracatus, as taieiras, os cucumbis" (WISSENBACH, 1993, p. 86).
Originalmente, o Tambor de Crioula apresentava a participação masculina de forma mais enfática na dança:

Em lugares do interior, ao lado da dança das coreiras, alguns homens executam pernadas ou rasteiras, também chamadas de pungas de macho, para derrubar companheiros ao chão. É por isso que alguns chegam a comparar a brincadeira com a capoeira. (FERRETTI ${ }^{\text {vii }}$, 2012).

O teórico Muniz Sodré (1998) explica que o "encontrão", umbigada ou semba (dialeto angolano) era dado também com a perna, caracterizando esse rito de dança e batuque, que mais tarde teria o nome de samba. Evidenciava-se a resistência à sociedade escravagista:

\footnotetext{
Nos quilombos, nos engenhos, nas plantações, nas cidades, havia samba onde estava o negro, como uma inequívoca demonstração de resistência ao imperativo social (escravagista) de redução do corpo negro a uma máquina produtiva $\mathrm{e}$ como uma afirmação de continuidade do universo cultural africano (SODRÉ, 1998, p. 12).
}

A riqueza material e simbólica do Tambor de Crioula fez com que a manifestação fosse preservada e que suas características adquirissem, inclusive, aspectos contemporâneos.

\section{“TAMBOR SECO, NÃO SENHOR”!}

Canto, dança e instrumentos compõem o Tambor de crioula. O conjunto - tambor grande, meião e crivador - é conhecido como parelha. Esses três tambores são de madeira 
(atualmente é possível encontrá-los em PVC), afunilados e cobertos com couro preso por cravelhas. "São denominados tambor grande, o solista, meião, o que estabelece o ritmo básico de 6/8, e o crivador, que realiza improvisos a 6/8" (IPHAN, 2009 ${ }^{\text {viii }}$ ).

A estrutura rítmica não é, realmente, simplória: "na música negra, a riqueza rítmica relega a segundo plano a melodia, que é simples, de poucas notas e frases pouco expressivas" (SODRÉ, 1998, p. 25). Ainda quanto à instrumentação, alguns grupos utilizam-se também de matracas e bastões de madeira, percutidos aos pares no corpo do tambor maior. Os tambores são afinados ao redor da fogueira:

\section{Isso é feito pelos seus próprios tocadores (coreiros), que repetidamente durante essa fase de aquecimento, percutem seus respectivos tambores até sentirem, pelo som emitido, a afinação ideal (FERRETTI, 2002, p.81).}

Os cantos são relacionados a trabalho, devoção, desafio, amor, dentre outros temas. Cada cântico começa com um solista, que interpreta toadas improvisadas ou conhecidas. Essas são repetidas e respondidas pelo coro, composto por homens que se substituem nos toques, e pelas mulheres dançantes, vestidas em saias rodadas com estampas coloridas, anáguas largas com renda e blusas rendadas, decotadas, coloridas ou brancas. "A cabeça enfeitada por flores, colares e outros adornos. Os homens usam camisas coloridas e chapéus de palha" (IPHAN, 2009 ${ }^{\mathrm{ix}}$ ).
Além desses elementos, comida e bebida são quesitos importantes para a festa da umbigada. Distribuir a comida (galinha, carne, tapioca, farofa, bolos) aos participantes e demais presentes significa seguir o exemplo de caridade do santo, além de demonstrar abundância e superação das dificuldades (IPHAN, 2009 ${ }^{\mathrm{x}}$ ).

Há também a bebida típica: a cachaça. O 'Não-Seca' é um filtro cheio da pinga com um copinho, mas não pode haver desperdício: "se encher tem que tomar!" (IPHAN, 2009 ${ }^{\mathrm{xi}}$ ).

Assim como outras manifestações, o Tambor de Crioula resiste, espalhando-se por várias cidades do estado do Maranhão. As músicas, danças africanas e demais riquezas culturais vão, entretanto, se modificando, perdendo alguns elementos e adquirindo outros, em função do ambiente social e cultural em que são desenvolvidas.

Há que se considerar, ainda, o caráter lúdico do Tambor de Crioula, com os brincantes, que são os coreiros e as coreiras, suas coreografias e adaptações ao longo do tempo:

\footnotetext{
(...) surgem saias com detalhes diferenciados, tambores industrializados (...), apresentações nos locais mais bem estruturados e expostos à mídia, além da utilização de uma literatura menos ligada à própria herança étnica ou à condição de classe, sendo que geralmente as idolatrias a padrinhos políticos integram o repertório de cada grupo. Enriquece-se a plástica e empobrecese a essência e o brilho arraigado do Tambor de Crioula (COSTA, 2006, p. 12).
} 
Nesse panorama contemporâneo, surge a preocupação com a tradição, em função da difusão do Tambor de Crioula por vários grupos, inclusive em outros estados. Isso demanda cuidados para que não haja uma grande descaracterização, conforme explica o Presidente do Conselho Cultural do Tambor de Crioula do Maranhão, Ubaldo Martins Gomes:

\begin{abstract}
(...) nossa função é justamente acompanhar o que vem acontecendo com esses Tambor de crioulo, com essas brincadeiras em cada lugarejo e fazer com que essa cultura seja forte em cada uma dessas unidades (GOMES In: FIGUEIREDO e OLIVEIRA, 2012 $2^{\text {xii }}$ )
\end{abstract}

Em maio de 2004, o dia 6 de setembro foi legitimado como Dia municipal do Tambor de Crioula e seus brincantes, com a aprovação pela Câmara Municipal de São Luís do Maranhão do projeto de lei no 51/04, de autoria do então vereador Ivan Sarney (PMDB). Após sua sanção, em 21 de junho do mesmo ano, o projeto foi oficializado como lei $n^{\circ} 4.349 / 04$. Dessa forma, incluía-se a data no calendário oficial dos eventos de cultura popular do Maranhão.

Em 2008, o Tambor de Crioula foi contemplado com selo comemorativo dos Correios, aprovado pela Comissão Filatélica Nacional, afinal, trata-se de um bem representativo da identidade cultural, conforme abordaremos em seguida.

\section{TAMBOR DE CRIOULA: PATRIMÔNIO INSTITUCIONALIZADO}

O Tambor de Crioula do Maranhão recebeu o título de Patrimônio Cultural Imaterial do Brasil, através do IPHAN, Patrimônio Histórico e Artístico Nacional, em 2007. Desde então, ações para a salvaguarda dessa manifestação estão sendo implementadas. As atitudes da sociedade civil são imprescindíveis, assim como o apoio governamental.

O Patrimônio Imaterial ou Intangível é a forma institucionalizada de reconhecimento das manifestações culturais, ou seja, compreende as tradições que comunidades, grupos e indivíduos recebem e repassam aos seus descendentes.

Há grande relevância nas tradições folclóricas, festas, línguas, indumentárias, nos saberes, costumes, gestuais, e em diversas outras manifestações transmitidas, recriadas coletivamente e modificadas ao longo do tempo, conforme ressalta a UNESCO, Organização das Nações Unidas para a Educação, a Ciência e a Cultura:

\footnotetext{
(...) Num mundo de crescentes interações globais, a revitalização de culturas tradicionais e populares assegura a sobrevivência da diversidade de culturas dentro de cada comunidade, contribuindo para o alcance de um mundo plural (UNESCO, s.d. ${ }^{\text {xiii }}$ )
}

Os queijos artesanais de Minas Gerais, o Círio de Nossa Senhora de Nazaré, a Feira de Caruaru, a Festa do Divino Espírito Santo 
de Pirenópolis (Goiás) e o Tambor de Crioula do Maranhão são exemplos de bens culturais imateriais registrados no Brasil. "A cultura agora transcende sua definição para o universo das práticas locais de simbolização e experimentação da realidade" (TURATTI e GODOY, 2012, p. 46).

O Brasil é vanguardista ${ }^{\text {xiv }}$ na introdução do conceito de imaterialidade na esfera patrimonial, bem como na consequente adoção de medidas jurídicas e técnicas para sua salvaguarda:

\begin{abstract}
(...) o artigo 216 da Constituição Federal de 1988 encampou simultaneamente a inovação conceitual que vinha se processando no campo preservacionista e a diversificação de categorias de bens patrimoniais e potencialmente patrimoniáveis, admitindo a distinção de bens culturais de natureza material $\mathrm{e}$ imaterial (TURATTI e GODOY, 2012, p. 47).
\end{abstract}

Os avanços conceituais e operacionais definidos em 1988 só foram concretizados a partir da edição do Decreto ${ }^{\circ} 3551$, de 4 de agosto de 2000, que instituiu o Registro de Bens Culturais de Natureza Imaterial. O IPHAN, então, tem como política federal de salvaguarda do patrimônio imaterial os mapeamentos e inventários de referências culturais; o registro, conforme formalizado no Decreto 3.551/2000; os planos e ações de salvaguarda $\left(\right.$ IPHAN $\left.^{\mathrm{xv}}\right)$.

O Tambor de Crioula integra, dessa forma, os bens intangíveis registrados no IPHAN, desde 20 de novembro de 2007, como registro das Formas de Expressão. São necessárias, entretanto, ações de planos de salvaguarda:

$$
\begin{aligned}
& \text {... as ações de salvaguarda do } \\
& \text { patrimônio imaterial promovem a } \\
& \text { visibilidade e a autoestima dos } \\
& \text { grupos sociais historicamente alijados } \\
& \text { dos espaços políticos e contribuem, } \\
& \text { assim, para o seu protagonismo } \\
& \text { social na formulação de demandas } \\
& \text { para obtenção de direitos (TURATTI } \\
& \text { e GODOY, 2012, p. 53). }
\end{aligned}
$$

Para salvaguarda do Tambor de Crioula uniram-se como parceiros a Secretaria de Estado de Cultura do Maranhão, Prefeitura Municipal de São Luís, Comissão Maranhense de Folclore, Federação das Entidades Folclóricas e Culturais do Estado do Maranhão, União dos Tambores de Crioula do Estado do Maranhão, o Conselho Cultural do Tambor de Crioula do Maranhão e a Associação de Tambor de Crioula.

\section{CONSIDERAÇÕES FINAIS:}

O Tambor de Crioula é uma das ricas manifestações culturais do estado do Maranhão, assim como o Bumba meu boi e as festas juninas. Evidenciamos nesse artigo as principais características do Tambor através do canto, da dança, da indumentária, dos instrumentos, das comidas e bebidas.

Se originalmente sua relevância era atestada como forma de resistência contra a dominação colonialista, inclusive com perseguição aos participantes por parte da polícia, posteriormente o Tambor de Crioula 
adquire também caráter lúdico. A sensualidade da dança bem marcada por uma rítmica peculiar evidencia-se no século atual com modificações, sobretudo na indumentária mais atraente e colorida.

Enquanto Patrimônio Cultural Imaterial do Brasil necessita, assim como todas as demais manifestações artísticas e culturais, de medidas de salvaguarda. Para isso, são necessários engajamentos entre setores da sociedade civil e governamental para garantia das condições políticas, administrativas e sociais. Essas ações devem ser continuadas para memória e vitalidade dos bens culturais imateriais registrados no Brasil.

\section{BIBLIOGRAFIA}

*CANTOS DE CONGO. Disponível em http://cantosdecongoitabira.blogspot.com.br/2 010/11/tambor-de-crioula.html

Imagem:

http://www.designup.pro.br/files/port/122649 3137.jpg Acessos em 05.01.2014.

COSTA, Rogério. Cultura Popular: Tambor de Crioula em links e sites. Trabalho apresentado na Jornada de Inovações Midiáticas e Alternativas Comunicacionais, do XXIX Congresso Brasileiro de Ciências da Comunicação, no período de 06 a 09 de setembro de 2006, na Universidade de Brasília - UNB.

ENCICLOPÉDIA DA MÚSICA BRASILEIRA. Punga. São Paulo: Art Editora, 1998. p. 646.

FERRETTI, Sérgio. Tambor de Crioula: ritual e espetáculo. São Luís: Comissão Maranhense de Folclore, 2002.
SODRÉ, Muniz. Claros e Escuros. Identidade, povo e mídia no Brasil. Petrópolis: Vozes, 1999.

Samba, o dono do corpo. Rio de Janeiro: Mauad, 1998.

TURATTI, Maria Cecília Manzoli e GODOY, Clayton Peron Franco de. Acarajé com mais recheio. In: SOCIOLOGIA. São Paulo: escala, 2011-2012. Ano IV. Edição 38. p. $45-53$.

WISSENBACH, Maria Cristina Cortez. Da Escravidão à Liberdade: Dimensões de uma Privacidade Possível. In: NOVAIS (coord) e SEVCENKO (org). História da Vida Privada no Brasil. República: da Belle Époque à Era do Rádio. São Paulo: Companhia das Letras, 1998. vol. 3. p. 50130.

\section{Referências eletrônicas e digitais:}

FERRETTI, Sergio. Ao som dos tambores. Herança dos escravos, o tambor-de-crioula resistiu aos preconceitos e continua agitando São Luís e o interior do Maranhão.

Disponível em

http://www.revistadehistoria.com.br/secao/arti gos/ao-som-dos-tambores. Acesso em 06.01.2014.

FIGUEIREDO, Kit e OLIVEIRA, Gabriel. Tambor de Crioula do Maranhão.

Disponível em http://www.youtube.com/watch?v=yhtHsZniy IE .Acesso em 06.01.2014.

G1MA. Dia Municipal do Tambor de Crioula será comemorado nesta sexta (6). Disponível em http://g1.globo.com/ma/maranhao/noticia/201 3/09/dia-municipal-do-tambor-de-crioulasera-comemorado-nesta-sexta-6.html Acesso em 07.01.2014.

GOVERNO DO MARANHÃO. Tambor-decrioula. Disponível em http://www.youtube.com/watch?v=RcGSkX5 MjEk Acesso em 05.01.2014. 
HAIKEL, Marco Aurélio. Breves Observações Sobre Tambor de Crioula. Disponível em http://www.capoeira.jex.com.br/cronicas/brev es+observacoes+sobre+tambor+de+crioula Acesso em 07.01.2014.

IPHAN. Departamento do Patrimônio Imaterial. Registro do Tambor de Crioula no Maranhão. Parecer técnico. http://portal.iphan.gov.br/portal/baixaFcdAne xo.do;jsessionid=9F244E6E5D7AF57DB9D4 C4D2013401B5? $\mathrm{id}=949$ Acesso em 06.01.2014.

Os sambas, as rodas, os bumbas, os meus e os bois. Princípios, ações e resultados da política de salvaguarda do patrimônio cultural imaterial no Brasil. Disponível em http://portal.iphan.gov.br/portal/baixaFcdAne xo.do?id=1800 Acesso em 08.01.2014.

\section{SECRETARIA DE POLÍTICAS DE PROMOÇÃO DA IGUALDADE RACIAL. Correios lançam Selo Comemorativo sobre o Tambor de Crioula. Disponível em http://www.seppir.gov.br/noticias/ultimas_not icias/2008/03/MySQLNoticia.2008-03-}

18.1713. Acesso em 07.01.2014.

UNESCO. Representação da UNESCO no Brasil. Disponível em http://www.unesco.org/new/pt/brasilia/culture /world-heritage/intangible-heritage/ Acesso em 08.01.2013.

\footnotetext{
${ }^{\mathrm{i}}$ A punga dos homens, ao contrário da punga das mulheres (umbigada), não acontece em todas as "brincadas de tambor", sendo encontrada mais comumente em comunidades rurais. Acontece ao lado da roda das mulheres, geralmente em areal e pode ser aplicada com intensidade variada. Mais informações em http://goo.gl/cchNaw

ii Benedito Manasseri nasceu em 1526, na pequena aldeia de São Fratelo, em Messina, na ilha da Sicília, Itália. Filho de africanos escravos vendidos na ilha, cresceu pastoreando rebanhos nas montanhas da ilha e, desde criança, demonstrava reverência a Deus e à religião, o que o fez ser chamado de: "Nosso santo mouro". Aos vinte e um anos de idade ingressou na Irmandade de São Francisco de Assis, em Palermo, capital da Sicília, tornando-se religioso. Passou a ser admirado pela população local pelos exemplos de solidariedade. No Brasil, é conhecido como São Benedito, o Negro, ou apenas "o Santo Negro". Foi canonizado em 1807 pelo papa Pio VII. Informações
}

disponíveis em http://www.paulinas.org.br/diafeliz/?system=santo\&id $=380$

iii Do folclore popular brasileiro, o Boi-Bumbá ou Bumba meu boi é fortemente desenvolvido no Maranhão. Possui personagens humanos e animais fantásticos, e o enredo aborda uma lenda sobre a morte e ressurreição de um boi.

${ }^{\text {iv }}$ Disponível em

http://www.capoeira.jex.com.br/cronicas/breves+obser vacoes+sobre+tambor+de+crioula

${ }^{v}$ Disponível em:

http://www.youtube.com/watch?v=yhtHsZniyIE

${ }^{\mathrm{vi}}$ Disponível online:

http://www.revistadehistoria.com.br/secao/artigos/aosom-dos-tambores

${ }^{\text {vii }}$ http://www.revistadehistoria.com.br/secao/artigos/aosom-dos-tambores

viii Disponível em http://migre.me/hkL8a

${ }^{\text {ix }}$ Disponível em http://migre.me/hkL8a

${ }^{\mathrm{x}}$ Disponível em http://migre.me/hkL8a

${ }^{x i}$ Disponível em http://migre.me/hkL8a

xii Disponível em

http://www.youtube.com/watch?v=yhtHsZniyIE

xiii Disponível em

http://www.unesco.org/new/pt/brasilia/culture/world-

heritage/intangible-heritage/

${ }^{\text {xiv }} \mathrm{O}$ patrimônio cultural imaterial do Brasil foi alvo de debates e propostas muito antes da sua conceituação na Constituição de 1988. Isso porque, desde a Semana de Arte Moderna, em 1922, Mário de Andrade já debatia sobre a necessidade de registro etnográfico da cultura popular para que ficasse preservada a diversidade cultural brasileira. Em 1938, à frente da Secretaria de Cultura da cidade de São Paulo, ele idealizou e executou a Missão de Pesquisa Folclórica, que recolheu manifestações (gravações e fotografias) da cultura popular do norte e nordeste (TURATTI e GODOY, 2012).

${ }^{\mathrm{xv}}$ Disponível em http://portal.iphan.gov.br/portal/baixaFcdAnexo.do?id= 1800 . 